\title{
Research on the Application of Causal Conjunctions in College Students' English Writing
}

\author{
Zhipeng Liu ${ }^{1 a^{*}}$, Xiaochen $\mathrm{Xu}^{2}$, Yongxiu Zhou ${ }^{1}$, Xinli $\mathrm{Li}^{1}$ \\ ${ }^{1}$ School of Foreign Languages, Taishan University, Taian, 271000, China \\ ${ }^{2}$ Basic Teaching Department, Shandong Electric Power College, Taian, 271000, China \\ alzp9980@163.com \\ ${ }^{*}$ Corresponding author
}

\begin{abstract}
Keywords: English majors students; non-English majors students; English writing; causal conjunctions
\end{abstract}

\begin{abstract}
This study compares the use of causal connection words in English writing between English majors and non-English majors in undergraduate colleges. It concludes that, causal connectives are used more frequently and more appropriately in English majors' writing; compared with non-English major students' writing, the use of causal connectives is diversified and complicated. This research has certain guiding significance for the rational use of logical semantic conjunctions in the future and improving the level of students' English work.
\end{abstract}

\section{Introduction}

In English discourse, the causal connectives act as a ligament of the logical semantic relations between the two clauses in the compound sentence. In the book "Connecting English", Halliday and Hasan (1976) systematically describe and detail the connection and coherence in English discourse. They proposed that, in the composition process of the discourse, the speaker uses the continuity methods of the textual structure in the text to achieve the unity and closeness of the discourse. Halliday divides these continuity methods in the discourse into five categories: indications, substitutions, omissions, connections, and lexical cohesion. These textual connection methods play an indispensable role in the text structure nearby the connection and promotion of the development of semantics. In the Nordic countries of Finland, Mauranen (1993) believes that students use the associated connectives significantly in English writing and use lexical cohesion more. Similarly, Altenberg et al. (1998) conducted a comparative study of conjunctions in discourse. By comparing the use of language conjunctions between different English learners in France and Finland, it was found that students' misuse of English conjunctions was common. . Crewe (1990) studied the English acquisition texts of Hong Kong students in China and found that Hong Kong students also used excessive use of causal conjunctions in the English writing of argumentative papers. Chinese scholar Chen Xinren (2002: 354) conducted in-depth and meticulous exploration and research on the use of causative conjunctions in English writing by domestic students, and found that Chinese English learners are affected by the interference of mother tongue to a certain extent, and the use of the causality words in the language is relatively rigidified. Pan Wangfan and Feng Yuejin (2004) used the research method of corpus to explore the writing texts of non-English majors. It was found that the use of English connectives also showed the phenomenon of less use or misuse of connected words. Throughout the study at home and abroad, English learners have used improper use of causal connectives in English writing. Based on this phenomenon, this paper compares the use of causal conjunctions in English and non-English majors in a college of China, analyzes and explores the characteristics and differences of students' causal conjunctions, and hopes to be referenced for college English teaching improvement in China. 


\section{Causal semantic relationship in English clauses}

\subsection{The representational form of causal semantic relations}

The representation of causal logical relations in systemic functional linguistics belongs to the category of conceptual meaning, which is a representation of semantic relations, expressing the connection between two clauses. For causal statements in English, conjunctions are a means of representing logical semantic relationships. If we remove the connection words, there will be obstacles in the cohesion and coherence of the whole sentence, and the logical and semantic relationship between the clauses will be unclear. This is because English is a form-based language, while Chinese is a semantic-based language, and the causal relationship between the clauses is more dependent on formal language structure. E.g:

We cannot let him to know the fact seeing that he has not been notified of the news.

In this clause, if we replace the causal phrase "seeing that" with "if", then the sentence is still correct. But in this case, the causal logical semantic relationship becomes a progressive meaning relationship, so the phrase that represents the logical semantics plays a very important role in expressing causality. Therefore, the omission of causal related words will leave a certain imaginary psychological space for the speaker, insert a certain logical semantic relationship between the two sentences, thus hindering the expression of the speaker's semantics, between the speaker and the listener.

\subsection{The order of causal clauses in English}

Word order refers to the linear logical order of words or structural components throughout the sentence. The word order in the sentence can represent the meaning relationship, grammatical relationship and rhetorical relationship between the various elements in the whole sentence, and even further represent the social meaning, cultural background connotation and pragmatic communication effect. However, from the perspective of sentence form, the central content of word order expression is still the content of formal grammar. In addition to grammatical and pragmatic factors, the determinants of word order can also be related to the national characteristics of the language community, the language conventions of the social groups and the language psychology. The causal relationship in English is as follows:

\subsubsection{Cause-based causal sentence}

2.2.1.1 Non-marked word order: The main clause is in the front, and the reason clause is in the back. He did not go to school because he was sick.

2.2.1.2 Marked word order: The main clause is in the back, and the reason clause is in the front Since he was dead, we will not work together with him.

This causal clause informs the reader that the reason for the matter is the content that the author wants to express strongly. Therefore, the reasoning of the preceding clause has a prominent effect and bears a certain rhetorical effect.

\subsubsection{Result-based causal sentence}

In the result-oriented causal clause, so that is used to characterize the logical semantic relationship between the preceding and following clauses in the complex sentence. And the resulting sub-sentences are usually placed after the entire sentence, that is, the word order is a non-marker word order, not a token word order. On the contrary, if we reverse and change the causal order before and after, then this semantic relationship will be changed. E.g.:

(1) Tom was coughing so bitterly that he did not breathe comfortably.

(2) That he did not breathe comfortably, Tom was coughing bitterly.

From a semantic point of view, (2) a sentence is a logically confusing clause representation, one is to violate the semantic relationship, and the other is not in line with the authentic English language expression. This is because in the logical semantics of English, so that is a fixed, conventional grammatical structure, and therefore cannot reverse the sentence order. 
Halliday and Hasan classify causal discourse markers based on the semantic and functional relationships between clauses. For example, there are simple forms in causality, such as so, then, hence, before, etc., although there are also some tagged words that can be used to indicate the cause, result, and purpose. Some causal words are familiar to us, such as because, before, then and so. Some words do not convey obvious causal meanings, but show the meaning of causality in the context of the reader and the audience, for example, in that case, here and otherwise. The following two sentences are explained by Halliday and Hasan:

(a) I was not informed. Otherwise I should have taken some action.

(b) It is the way I like to go to work. One person and one line of enquiry at a time. Otherwise, there's a muddle. $(1976,259)$

\section{Design plan}

\subsection{Researching issue}

According to the standard classification Quirk (1985) and Xing Fuyi (1997) based on grammar, semantics and function, the causal conjunctions are divided into three categories: conjunctions or conjunctional phrases, adverbs or adverbial phrases, and prepositional phrases. This classification method accurately divides the causal semantic relationship between sentences, but it does not elaborate and completely explain the causal relationship problem in complex discourse. Therefore, this paper uses the classification method of Kennedy (1992: 68) for statistics and differentiation.

Table 1 the classification of causal conjuctions

\begin{tabular}{|l|l|l|}
\hline \multicolumn{1}{|c|}{ Word attribute } & \multicolumn{1}{|c|}{$\begin{array}{c}\text { Vocabulary } \\
\text { function }\end{array}$} & \\
\hline $\begin{array}{l}\text { Conjunction or } \\
\text { Conjunctional } \\
\text { phrase }\end{array}$ & Result & Cause \\
\cline { 2 - 3 } $\begin{array}{l}\text { Adverb or } \\
\text { adverbial phrase }\end{array}$ & Result & As, for, because, since, now that \\
\hline $\begin{array}{l}\text { Prepositional } \\
\text { phrase }\end{array}$ & Result & As a consequence, as a result, hence, so, therefore, thus \\
\cline { 2 - 3 } & Cause & As a consequence, as a result \\
\hline
\end{tabular}

This study mainly addresses the following two issues:

1) The current situation and characteristics of the use of causal conjunctions in English writing for English majors and non-English majors in China.

2) Compare the English work of English majors and non-English majors in China, and explore the differences in the distribution of causal conjunctions.

\subsection{Researching steps}

In view of the differences between the English writing of English majors and the academic writing of non-English majors, the author classifies the collected texts and conducts computer analysis and comparison procedures. I have designed a small corpus A1 and A2 according to the needs of teaching and research. This corpus collects and organizes the actual samples of students' English works. This paper uses the cluster sampling method to refer to the grades of the students of the foreign language colleges of a local college. Each grade randomly selects the text corpus A1 of three classes, a total of 245 works, the total number of words is 80,000 characters, the writing topic is "Time is precious". Similarly, we randomly selected the English corpus A2 of non-English majors in all grades, a total of 276 works, the total number of words is also 80,000 characters, and the essay topic is also "Time is precious".

Use the search software Wordsmith Tools 4 to retrieve the causal conjunctions contained in the text, and then use the manual retrieval method to exclude words that are not suitable for this study that 
are obviously not causal meaning. The conjunction "as" is used as an example. While this word can be used to indicate causality, it can also indicate accompanied and chronological order, so such related words can be excluded.

\section{Analysis of Distribution Frequency of Causal Connectives}

According to the classification method of Kennedy (1992:68), we use the search software Wordsmith Tools 4 to retrieve the causal conjunctions contained in the text, and then use manual retrieval to exclude the vocabulary obvious meaning of causal connection that is not suitable for this study. Based on the corpus, the representational column table of the frequency of the causal conjunctions is shown as follows:

Table 2 the frequency of the causal conjunctions

\begin{tabular}{|c|c|c|c|c|}
\hline \multirow[b]{3}{*}{ Causal vocabulary } & \multicolumn{4}{|c|}{ Frequency } \\
\hline & \multicolumn{2}{|c|}{ English major A1 } & \multicolumn{2}{|c|}{ non-English major A2 } \\
\hline & $\begin{array}{l}\text { Actual } \\
\text { frequency }\end{array}$ & $\begin{array}{l}80,000 \text { words relative } \\
\text { frequency }\end{array}$ & $\begin{array}{l}\text { Actual } \\
\text { frequency }\end{array}$ & $\begin{array}{l}80,000 \text { words relative } \\
\text { frequency }\end{array}$ \\
\hline as & 24 & 5 & 13 & 17.8 \\
\hline because & 946 & 193 & 128 & 162 \\
\hline due to & 25.6 & 6.1 & 22.4 & 29.2 \\
\hline for & 8.8 & 18.4 & 21.6 & 28 \\
\hline hence & 11.2 & 2.3 & 0.8 & 1.0 \\
\hline now that & 5.6 & 1.12 & 0.1 & 0.1 \\
\hline since & 66 & 1.35 & 13.5 & 17.7 \\
\hline so & 1511 & 309 & 195 & 255 \\
\hline therefore & 132 & 26.7 & 43.9 & 58.2 \\
\hline thus & 122 & 25.1 & 23.1 & 30.2 \\
\hline thereby & 0.8 & 0.15 & 0 & 0 \\
\hline
\end{tabular}

From the word frequency distribution of the logical semantic causal relationship in the above table, the English major learner's conjunction effect is obviously stronger than the non-English major students. English major students are not only stronger in the use of commonly used causal words (as, because, so), but also in other complex causal words (therefore, thus, such). There are significant differences between the two types of students in the use of causal conjunctions, such as "therefore" and "thus". The causal conjunction "therefore", the frequency of English major learners is 132, and the frequency of non-English major learners is 43.9. Similarly, English majors use the word "thus" for 122 times, whereas non-English majors use 23.1 times. In the above table, we also found a special phenomenon, that is, in the use of the relational conjunction "for", the frequency of non-English major learners is higher than that of English major learners, the former frequency of use is 21.6 times, and then the frequency of use is 8.8 times. This phenomenon indicates that non-English majors tend to express the reason clause in the simplest form of markup, confusing the use of "for" prepositions with the use of conjunctions.

Through data survey and analysis, English majors can use causal conjunctions effectively and reasonably. They usually use "so", "because", etc. to express causality. However, from their corpus, some connected words are misused, such as:

\section{(1) I bought an apple, so my sister got home.}

Obviously, the clauses before and after "so" have no causal relationship on the semantic connection, so this is wrong.

(2) Because I recall the companions in the company, so I encourage all the members of my companions to celebrate my birthday.

From the perspective of logical semantic analysis in words and phrases, the use of causal conjunctions is obviously wrong, and does not conform to the principle of functional semantics between before and after clauses.

It is worth noting that two types of English learners prefer words like "therefore", "so" and "thus" in the use of causal words, and use less for causal vocabulary like "hence", "in consequence", "as a 
result", "consequently" and "accordingly". Domestic English learners tend to use simple, easy-to-remember and proficient discourse markers in the use of causal words. He Anping and Xu Manfei (2003: 451) also reached similar conclusions through their own research: Chinese English learners are accustomed to using simple and easy to grasp discourse markers.

As we all know, in actual language teaching, teachers usually teach causality markers to students without context, which is why learners are only familiar with its semantics, but do not understand its actual contextual meaning. This study can provide reference for English learners to improve the use of causal connectives and improve the textual advancement model under the guidance of logical semantics. First, when teaching a causal discourse marker, teachers should not only explain the isolated causality markup, but put it into a specific context for analysis and interpretation. At the same time, the causal relationship reflected by the lexical signal should also be interpreted as the learner can grasp the causality mark associated with certain causal relationships and be familiar with its practical application in the real language environment.

\section{Conclusion}

By comparing and analyzing the word frequency representation of causal conjunctions in English major and non-English major learners, this paper draws the following conclusions: in the writing of argumentative papers, the frequency of causal conjunctions of English major learners is significantly higher than that of non-English major learners. This also shows that Chinese English majors perform better than non-English major students in the mastery and application of causal connectives. In the study, students must consciously choose different discourse markers according to the different linguistic contexts, combined with certain social structures, to express causal logical relationships and linguistic thinking. In the future teaching of English writing, teachers should pay great attention to related conjunctions, especially causal conjunctions, and adopt different teaching strategies for different teaching environments and language learners.

\section{Acknowledgement}

This research was financially supported by 2017 Shandong Provincial Higher Education Research and Development Program (Humanities and Social Sciences) - "Research on the Constructive Function of Causal Relationship in Academic English Writing" (No. J17RA062); Shandong Social Science Planning Research Project "College English Curriculum Design and College Students Self-study Research on the Correlation of Efficacy (12CWJJ01)2015 Taishan University College Teaching Reform Research Project--"Research on English Vocabulary Learning Practice of College Students Based on Learning Strategy Training" (No. 201520); The Tenth Taishan University Teaching Reform Research Project - "Study on the Discourse of College English Teachers' Views Based on Critical Discourse Analysis Theory" (No. 201723)

\section{References}

[1] Altenberg, B. \&M. Tapper.The Use ofAdverbial Connectors inAdvancedLearner's Written English[M]. London and New York: Longman, 1998.

[2] Crewe, W. J. The illogic of logical connectors[J].EFLJournal,1990,(44):316-325.

[3] Halliday,M. A. K. \&R. Hasan.Cohesion in English[M]. Beijing: Foreign Language Teaching and Research Press, 1976.

[4] Kennedy. Expressing causation in written English[J].RELCJournal, 1992,23(1):68.

[5] Mauranen, A.CulturalDifferences inAcademicRhetoric:ATextlinguisticStudy[M]. Frankfurt: PeterLang, 1993. 
[6] Quirk, R.AComprehensive Grammar ofthe English Language[M]. London and NewYork: Longman, 1985.

[7] He Anping Xu Manfei. Research on Small Words in Chinese College English Oral English. Foreign Language Teaching and Research, 2003, (6). (In Chinese)

[8] Chen Xinren. Discourse Connectives and English Argument Writing: Investigation and Analysis. Foreign Language Teaching and Research, 2002, (5). (In Chinese)

[9] Pan Wangfan, Feng Yuejin. A Corpus Survey of the Use of Connectives in Non-English Majors' Writing[J]. Modern Foreign Languages, 2004, (2). (In Chinese)

[10]Xing Fuyi. Chinese Grammar. Harbin: Northeast Normal University Press, 1997. (In Chinese) 